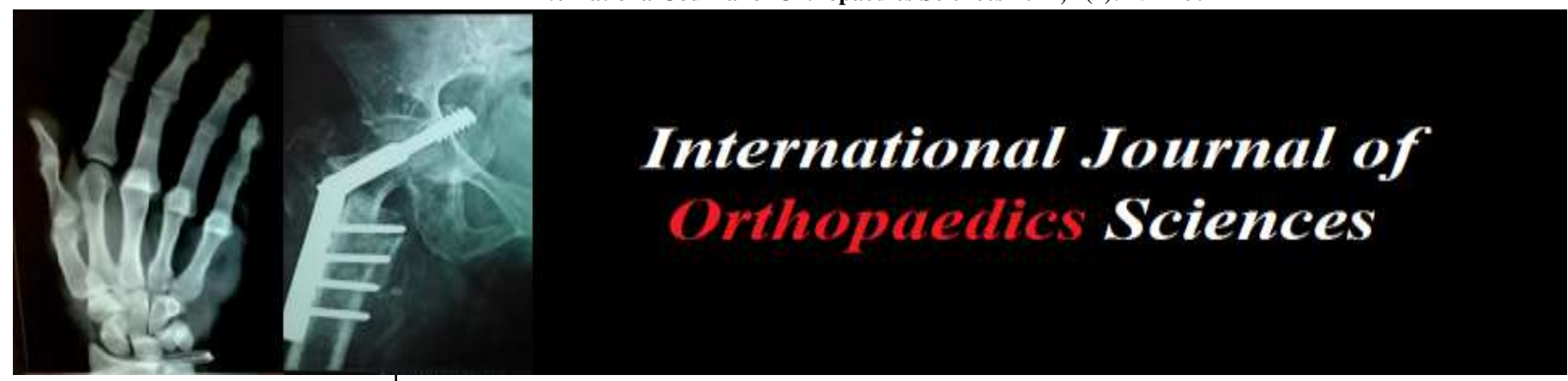

E-ISSN: 2395-1958

P-ISSN: 2706-6630

IJOS 2021; 7(1): 454-460

(C) 2021 IJOS

www.orthopaper.com

Received: 26-10-20

Accepted: 06-12-2020

Dr. Surendra Babu S MS (Orthopaedics),

Koramangala, Bangalore, Karnataka, India

Dr. Tarun Desai

MS (Orthopaedics),

Koramangala, Bangalore,

Karnataka, India

Dr. Kaushik YS

Koramangala, Bangalore, Karnataka, India
Corresponding Author: Dr. Tarun Desai MS (Orthopaedics) Koramangala, Bangalore, Karnataka, India

\section{Short to midterm functional outcome of unipolar uncemented hemiarthroplasty versus bipolar uncemented hemiarthroplasty in displaced fracture neck of femur in elderly individuals}

\author{
Dr. Surendra Babu S, Dr. Tarun Desai and Dr. Kaushik YS
}

DOI: https://doi.org/10.22271/ortho.2021.v7.i1h.2524

\begin{abstract}
Background: Hemiarthroplasty (HA) is best treatment option for fracture neck of femur in elderly individuals above 60 years with early mobilisation and less complications associated with internal fixation. However, there is inadequate evidence to support the choice between unipolar or bipolar HA. This study is aimed primarily at comparing the post-hemiarthroplasty functional results in subjects with fracture neck of femur using 'Austin-Moore's and bipolar prosthesis and studying the associated complications.

Methods: 55 subjects who were admitted between October 2014 to august 2016, operated with AustinMoore's prosthesis were allocated to Group A and subjects operated with bipolar Prosthesis were allocated to Group B, in K.R.HOSPITAL, Mysore Medical College, Mysore. All subjects were functionally assessed using the Harris Hip Score (HHS) and complications, if any, were documented. Xray pelvis with both hip in anteroposterior view taken.

Results: In this study, mean age in Unipolar and Bipolar group was 76 and 72 years respectively. The mean Harris hip score in unipolar and bipolar groups was 84 and 92 respectively. There were no major differences in functional activities in either group, bipolar group has slightly better functional outcome which is statistically insignificant. In unipolar group there is marginal increase in chances of acetabular erosion. Complications rate is similar in both groups.

Conclusions: Based on the results of our study, unipolar and bipolar has its own advantages and disadvantages, we recommend unipolar arthroplasty in less ambulatory, low socioeconomic status, subjects with short life expectancy. Bipolar-arthroplasty in elderly medically fit individuals who are physically active.
\end{abstract}

Keywords: Bipolar hemiarthroplasty, unipolar hemiarthroplasty, Harris hip score, neck of femur fracture

\section{Introduction}

Fractures of the neck of the femur are one of the common fractures encountered by an orthopaedic surgeon. The incidence of these fractures and the problems subsequent to them seems to be increasing; the cause of this is mainly the increase in elderly population in whom osteoporosis is prevalent. There are high chances that the fracture neck femur will progress to non-union or avascular necrosis due to precarious blood supply, lack of cambium layer of periosteum, effect of synovial fluid and tamponading effect of the intracapsular hematoma. Reduction and internal fixation of the fractures is the treatment of choice in younger subjects whereas primary arthroplasty is better in case of elderly even with undisplaced fractures to avoid problems of prolonged recumbency and have a faster rehabilitation. In displaced fractures there are high chances of avascular necrosis and non-union leading to a high failure rate ${ }^{[1,2,3]}$ re-operation rate ${ }^{[2]}$, poor functional outcome ${ }^{[3]}$ and mortality ${ }^{[4]}$. Hence primary arthroplasty is recommended for displaced fractures of the neck of femur ${ }^{[3]}$ in elderly subjects. With various options available like unipolar, bipolar or total hip arthroplasty, it would be wise to choose hemiarthroplasty as it is a procedure with a short operating time with lesser morbidity and is suitable in subjects with lesser life expectancy ${ }^{[5]}$. Hemiarthroplasty of the hip was ushered into widespread use in 1943 by Moore and Bohlman, who reported fashioning a custom metallic femoral head and neck prosthesis for a subject suffering from a proximal femoral shaft tumor ${ }^{[6]}$. 
Forerunner of these prostheses was the unipolar replacement of the femoral head, which was used in the 1940's by Judet and Judet. Subsequently, commercially available fixed head endoprosthesis have acquired widespread popularity, especially the Moore and Thompson hip endoprosthesis. Their placement has subsequently become acceptable treatment for acute displaced femoral neck fracture in elderly subjects or for acute femoral neck fracture in neurologically handicapped or poor surgical risk subjects ${ }^{[6]}$. Austin Moore and Thomson's hemiarthroplasty have given good results. But in these prostheses, it is the head size which decides the size of the stem which will fit in the femur. This lack of modularity and problems like joint pain, acetabular erosion, protrusion acetabuli, has led to a decrease in their use. In 1974, James Bateman introduced the bipolar prosthesis. The complication of acetabular erosion and pain are reduced by use of bipolar prosthesis, but the cost still precludes its use especially for subjects from lower economic strata in India. Wathne and coworkers ${ }^{7}$ could identify no differences in the perioperative care, revision rates or the 1-year outcomes in a prospective study comparing 140 elderly subjects treated with either bipolar or unipolar prosthesis. They reported no advantages identified in using the bipolar device, despite a greater cost. More over there is increasing literature which state about loss of movement between the two bearing surfaces of a bipolar, which ultimately functions as a unipolar. Thus, this study is aimed primarily at comparing the functional results obtained after a hemiarthroplasty in elderly subjects with displaced fracture neck of femur using Austin Moore's prosthesis and bipolar prosthesis and studying the associated complications in these cases.

\section{Aims and objectives}

To study short to midterm functional results obtained after hemiarthroplasty in displaced intracapsular neck of femur fractures in elderly subjects using un-cemented Austin Moore's prosthesis and un-cemented non-modular bipolar prosthesis with the help of Harris Hip score and to study associated complications in these cases.

\section{Material and methods}

A Prospective Comparative Study" was conducted at K.R. HOSPITAL, Mysore Medical College, Mysore, the period from October 2014 to august 2016 (24 months of recruitment) and followed up for 36 months till October 2019. Written consent was taken from all subjects for publication of clinical and radiological data and ethical committee and research committee appropriate permissions taken.

Study sample size: 55 elderly subjects who were admitted between October 2014 to august 2016, who met inclusion criteria were included in the study and operated. Subjects operated with Austin Moore's prosthesis were allocated to Group A and subjects operated with bipolar Prosthesis were allocated to Group B. 28 subjects were allocated into group A and 27 subjects were allocated to Group B according to randomized tables. 5 subjects were died before final follow up, 3 from Group A and 2 from Group B. 50 subjects completed final follow up 36 months postoperatively.

\section{Inclusion criteria}

1. Male and female subjects of age 60 and above

2. Displaced intracapsular neck of femur fracture with adequate calcar.

3. Neglected intracapsular neck of femur fracture not more than 6 weeks old in elderly subjects.

\section{Exclusion criteria}

1. Fracture of the neck of the femur in younger subjects.

2. Subjects associated with ipsilateral or contra lateral fracture of upper and lower extremities

3. Subject with neurological disorders.

\section{Pre-operative protocol}

Subjects were initially screened in the casualty or out subject department. Anteroposterior X-rays of pelvis with both hips with affected hip in $15^{\circ}$ internal rotation and X-ray of affected femur and knee- Anteroposterior views were taken. All subjects with displaced intracapsular neck of femur fractures were initially immobilized with skin traction. Routine hematological investigations, chest X-ray, ECG, ECHO and USG venous Doppler were done. Assessment of fitness was done by the Anesthetist and Physician. The subjects were graded as per the American Society of Anesthesiologists (ASA) Scores.

All subjects were treated surgically with Hemiarthroplasty using the Austin Moore's/Bipolar prostheses with the Posterolateral approach. Intravenous Antibiotics - 1 dose of injection Cefuroxime axetil $1.5 \mathrm{gm}$ and injection Amikacin $500 \mathrm{mg}$ on previous night and same dose repeated just before starting surgery.

\section{Operative protocol}

Anaesthesia: spinal / epidural / General Anaesthesia

\section{Surgical procedure}

Position: lateral, with support braces at pelvis and thorax and bony prominences protected with cotton pad.

Preparation: First with betadine scrub, later povidone iodine solution and spirit of entire limb with gluteal region and later covered with sterile drapes.

The posterolateral approach was used for hemiarthroplasty as it gives adequate exposure with minimal bleeding. The incision starts about $8 \mathrm{~cm}$ anterior to posterosuperior iliac spine extends to greater trochanter and then along the course of shaft femur $10 \mathrm{~cm}$ distal to greater trochanter. The subcutaneous tissue is divided along the skin in a single plane down to the fascia lata and thin fascia covering the Gluteus Maximus. Fascia, gluteal and femoral bursae are divided in line with the skin incision. The interval between the posterior border of Gluteus Medius and anterior border of Gluteus Maximus is entered. 


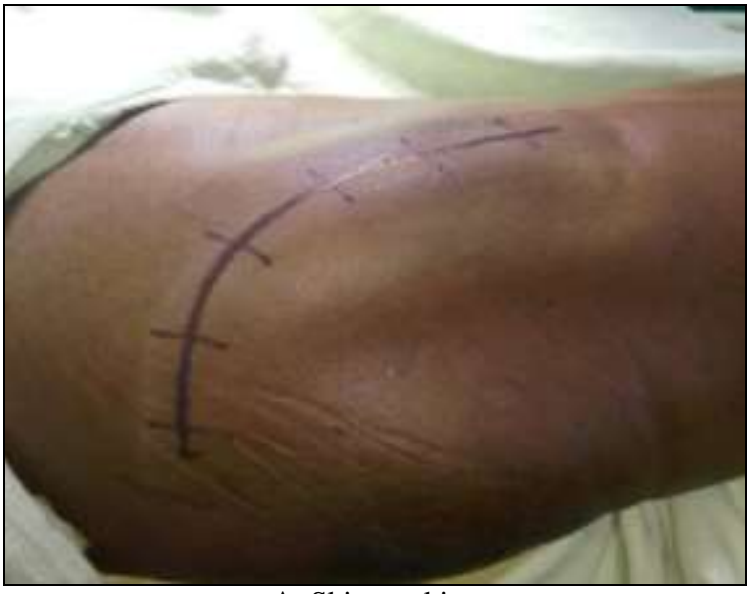

A. Skin marking.

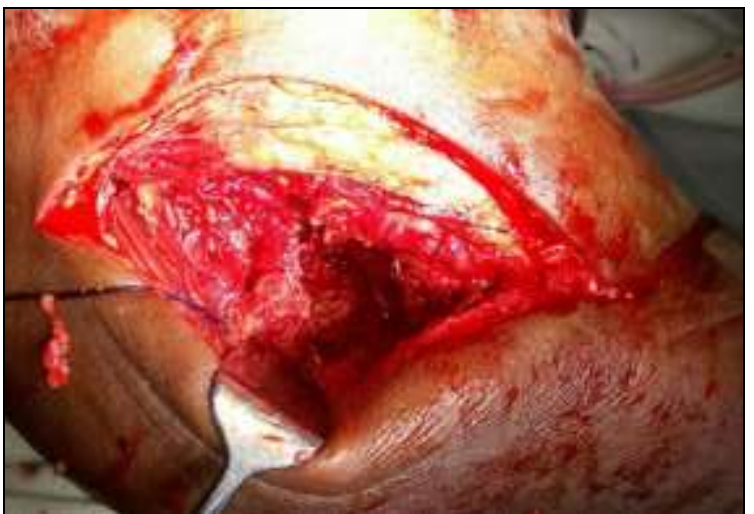

C. External rotators tied and excised.

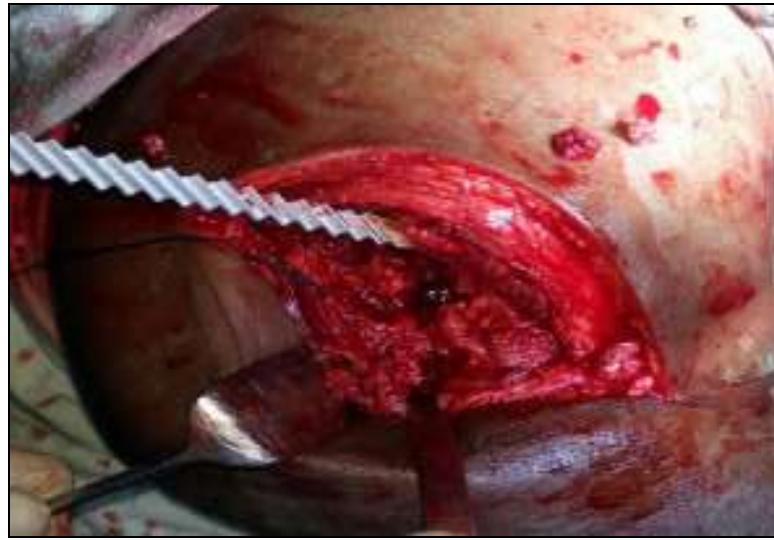

E. Broaching of femur

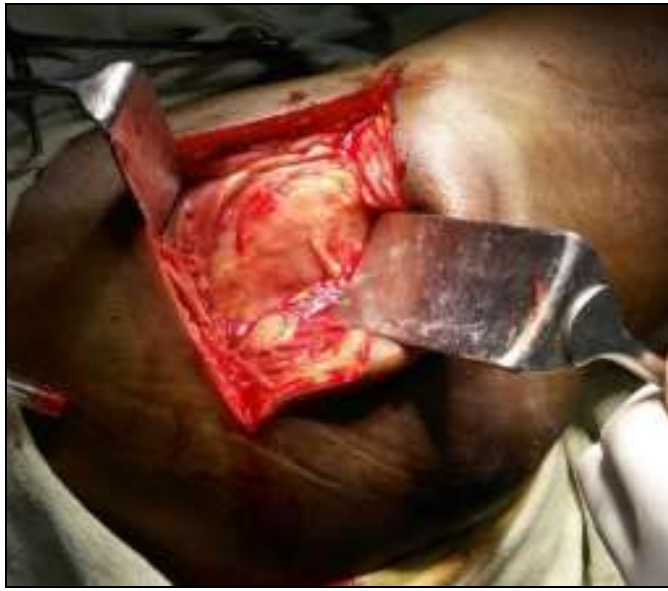

B. Gluteus Maximus is exposed

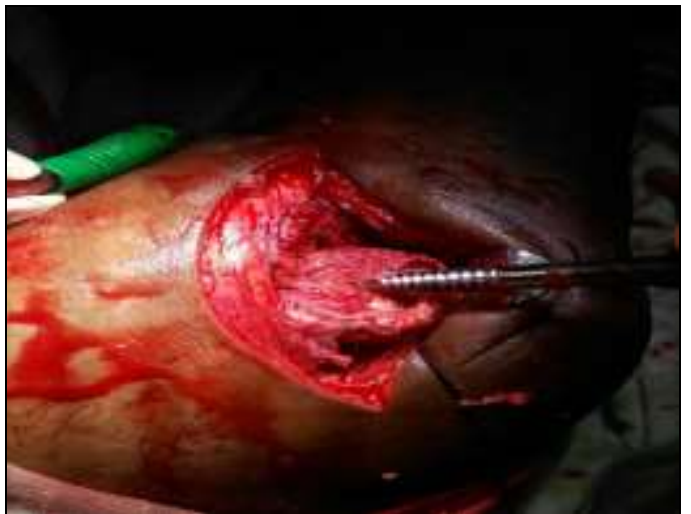

D. Head extraction

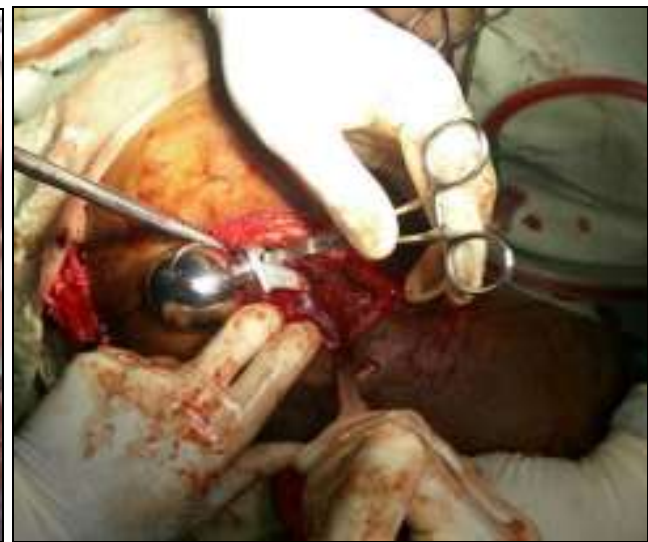

F. Final implantation

Fig 1A-F: Surgical steps

The short external rotator muscles - piriformis, gemelli and obturators are detached close to their insertion by maximum internal rotation of the limb, with electric cautery close to the bone. They are reattached to femur with drill holes during closure of wound.

Inverted T-shaped incision is made in the joint capsule and care to protect the sciatic nerve. Fully exposed femoral neck is supported with retractors.

Head removed with extractor, size of head measured with gauge, cotton plug put inside acetabulum to prevent lodging of bone pieces in it.

Appropriate Neck cut made above the lesser trochanter with extension to greater trochanter with preservation of calcar taken with oscillating saw as required.

Entry point is made as lateral as possible in line with the inner wall of the lateral cortex.

Femoral canal prepared using straight reamers followed by serial broaching up to appropriate size, A head size is confirmed by measuring the extracted femoral head using the sizing jig. The head sizing rings through which the extracted head cannot pass is the correct size of the head. Trial Austin Moore prosthesis is reduced to acetabulum to check appropriate head size by felling suction effect in the acetabulum.

Appreciate size prosthesis inserted into femur medullary canal, Joint is relocated with gentle traction to limb, gentle push over head with external rotation of limb reduces prosthesis to acetabulum.

Joint movements and stability checked. Capsule is closed in all cases. Pyriformis and short external rotators are reattached via drill holes in femur.

Negative suction drain tube is kept extracapsularly after reattaching the short rotators. Intermittent stitches taken for gluteus muscle and ilio-tibial band.

Subcutaneous tissue and skin are closed in layers. 


\section{Post-Operative Protocol}

Post-operative and mobilization protocol was same for all subjects. Antibiotics, analgesics and other drugs used as required. Leg in $30^{\circ}$ abduction with a pillow kept between the thighs.

Foot end elevation for one day. Prophylaxis for Deep vein thrombosis in high-risk subjects. Post-operative AnteroPosterior X-ray of operated hip. Post-operative investigations as required.

Active exercises in bed for quadriceps, ankle pump exercises, pelvis bridging exercises and breathing exercises. Drain removal after 48 hrs. Sitting on 1st day with active and passive exercises in bed. Partial to full weight bearing walking on operated side with the help of a walker from 2nd day onwards according to pain tolerance. Postoperative dressings as required.

Suture removal on or after 15 days. Subject discharged after full rehabilitation. Prior to discharge check done for late clinical sepsis and deep vein thrombosis.

\section{Follow-up protocol}

Post-operative visits were scheduled at 6 weeks, 3 months, 6 months, 12 months, 24 months and 36 months. Clinicoradiological and functional assessments were carried out. All subjects were functionally assessed using the Harris Hip Score (HHS) and complications, if any, were documented. Xray pelvis with both hip in anteroposterior view taken.

HHS is Point scale with maximum of 100 points: Pain 44, Function 47, Range of motion 05, Absence of deformity 04.

\section{Results}

Following are the details of clinical information collected from our study. Out of 55 cases enrolled in the study. 5 subjects were died before final follow up, 3 from Group A and 2 from Group B.

Of 55 subjects, there were 30 females and 25 males. The youngest subject in our series was 60 years and the oldest 90 years. The average age of the subject was 76 years in Group A and 72 years in Group B.

Table 1: Age incidence

\begin{tabular}{|c|c|c|c|c|}
\hline Age Groups & \multicolumn{2}{|c|}{ Austin Moore } & \multicolumn{2}{c|}{ Bipolar } \\
\hline & No. of Cases & Percentage & No. of Cases & Percentage \\
\hline $60-64$ & 5 & $17.8 \%$ & 7 & $25.9 \%$ \\
\hline $65-69$ & 6 & $21.4 \%$ & 7 & $25.9 \%$ \\
\hline $70-74$ & 5 & $17.8 \%$ & 5 & $18.5 \%$ \\
\hline $75-79$ & 7 & $25 \%$ & 4 & $14.8 \%$ \\
\hline 80 \& Above & 5 & $17.8 \%$ & 4 & $14.8 \%$ \\
\hline Total & 28 & $100 \%$ & 27 & $100 \%$ \\
\hline
\end{tabular}

Table 2: Sex Incidence

\begin{tabular}{|c|c|c|c|c|}
\hline & \multicolumn{2}{|c|}{ Austin Moore } & \multicolumn{2}{c|}{ Bipolar } \\
\hline Sex & No. of Cases & Percentage & No. of Cases & Percentage \\
\hline Female & 18 & $64.2 \%$ & 12 & $44.4 \%$ \\
\hline Male & 10 & $35.8 \%$ & 15 & $55.6 \%$ \\
\hline Total & 28 & $100 \%$ & 27 & $100 \%$ \\
\hline
\end{tabular}

Table 3: Complications

\begin{tabular}{|c|c|c|}
\hline Complications & Austin Moore & Bipolar \\
\hline Superficial infections & $2(7.1 \%)$ & $2(7.4 \%)$ \\
\hline Pneumonia & $2(7.1 \%)$ & - \\
\hline Sciatic nerve paresis & - & $2(7.4 \%)$ \\
\hline Dislocation & $2(7.1 \%)$ & $1(3.7 \%)$ \\
\hline Acetabular erosion & $2(8 \%)$ & - \\
\hline Peri prosthetic fracture & - & - \\
\hline
\end{tabular}

The subjects walked (partial weight bearing) on an average 3 days after surgery. Four subjects in this study developed superficial infection two in each group. All of them settled down with 2 weeks of intravenous antibiotics. Two subjects of Group A developed pneumonia which settled down with intravenous antibiotics.

Two subjects of Group A had dislocation one at 1st week and another at $2^{\text {nd }}$ week post-operatively due to subject noncompliance. It was treated by closed reduction. One subject of Group B had dislocation at 1 month postoperatively due to trivial trauma which had to be open reduced due to failure of closed reduction.

Two subjects of Group B developed sciatic nerve paresis both recovered completely at final follow-up.

Two subjects from Group A developed Grade I acetabular erosion at final follow up without significant pain and loss of range of motion.

Out of the 55, 1 subject from both groups expired due to myocardial infarction with in 6 months of follow up. 1 subject from group A developed stroke and expired 18 months of surgery, 1 subject from both groups expired after 24 months follow up due to unknown cause. Remaining 50 subjects were followed up for minimum of 36 months.

No loosening, peri prosthetic fracture or deep infections occurred in either group till last follow up in our study.

Table 4: Association of age group with final outcome

\begin{tabular}{|c|c|c|c|c|c|c|c|c|c|c|}
\hline \multirow[b]{2}{*}{ Age Group } & \multirow[b]{2}{*}{$\begin{array}{c}\text { No. of } \\
\text { Subjects }\end{array}$} & \multicolumn{4}{|c|}{ Austin Moore } & \multirow[b]{2}{*}{$\begin{array}{c}\text { No. of } \\
\text { Subjects }\end{array}$} & \multicolumn{4}{|c|}{ Bipolar } \\
\hline & & $\begin{array}{c}\text { Excellent } \\
\text { No \% }\end{array}$ & $\begin{array}{c}\text { Good } \\
\text { No \% }\end{array}$ & $\begin{array}{c}\text { Fair } \\
\text { No \% }\end{array}$ & $\begin{array}{l}\text { Poor } \\
\text { No \% }\end{array}$ & & $\begin{array}{c}\text { Excellent } \\
\text { No \% }\end{array}$ & $\begin{array}{l}\text { Good } \\
\text { No \% }\end{array}$ & $\begin{array}{c}\text { Fair } \\
\text { No \% }\end{array}$ & $\begin{array}{l}\text { Poor } \\
\text { No \% }\end{array}$ \\
\hline $60-64$ & 5 & $2(40)$ & $3(60)$ & $0(0)$ & $0(0)$ & 7 & $4(57.4)$ & $3(42.6)$ & $0(0)$ & $0(0)$ \\
\hline $65-69$ & 6 & $2(33.3)$ & $4(66.6)$ & $0(0)$ & $0(0)$ & 7 & $6(85.7)$ & $1(14.3)$ & $0(0)$ & $0(0)$ \\
\hline $70-74$ & 5 & $2(40)$ & $2(40)$ & $1(20)$ & $0(0)$ & 5 & $3(60)$ & $2(40)$ & $0(0)$ & $0(0)$ \\
\hline $75-79$ & 5 & $2(40)$ & $2(40)$ & $1(20)$ & $0(0)$ & 3 & $1(33.3)$ & $2(66)$ & $(0)$ & $0(0)$ \\
\hline $80 \&$ Above & 4 & $1(25)$ & $2(50)$ & $1(25)$ & $0(0)$ & 3 & $1(33.3)$ & $0(0)$ & $2(66)$ & $0(0)$ \\
\hline
\end{tabular}


In our study Group A has $88 \%$ excellent to good result, 3 subjects $(12 \%)$ has poor result at final follow up, all are above 70 years of age. In Group B $92 \%$ has excellent to good result at final follow up.

Table 5: Functional outcome at final follow up

\begin{tabular}{|c|c|c|c|c|c|c|c|c|}
\hline 12 Months & \multicolumn{2}{|c|}{ Poor } & \multicolumn{2}{c|}{ Fair } & \multicolumn{2}{c|}{ Good } & \multicolumn{2}{c|}{ Excellent } \\
\hline Prosthesis Type & Number & $\%$ & Number & $\%$ & Number & \% & Number & \% \\
\hline Austin Moore & 0 & $0 \%$ & 4 & $16 \%$ & 10 & $40 \%$ & 11 & $44 \%$ \\
\hline Bipolar & 0 & $0 \%$ & 2 & $8 \%$ & 7 & $28 \%$ & 16 & $64 \%$ \\
\hline
\end{tabular}

Table 6: Association of ambulatory subjects with outcome

\begin{tabular}{|c|c|c|c|c|c|c|c|c|c|c|}
\hline \multirow[b]{2}{*}{ Ambula-Tory Status } & \multirow[b]{2}{*}{ No. of Patie-Nts } & \multicolumn{4}{|c|}{ Group A } & \multirow[b]{2}{*}{ No. of Pati-Ents } & \multicolumn{4}{|c|}{ Group B } \\
\hline & & \begin{tabular}{|c|} 
Excel Lent \\
No $(\%)$
\end{tabular} & \begin{tabular}{|c|} 
Good \\
No $(\%)$
\end{tabular} & $\begin{array}{c}\text { Fair } \\
\text { No }(\%)\end{array}$ & $\begin{array}{c}\text { Poor } \\
(\%)\end{array}$ & & $\begin{array}{c}\text { Excel Lent } \\
\text { No }(\%)\end{array}$ & $\begin{array}{c}\text { Good } \\
\text { No }(\%)\end{array}$ & $\begin{array}{c}\text { Fair } \\
\text { No }(\%)\end{array}$ & $\begin{array}{c}\text { Poor } \\
\text { No }(\%)\end{array}$ \\
\hline \multirow{2}{*}{ House-Hold } & \multirow{2}{*}{13} & 5 & 4 & 4 & 0 & \multirow{2}{*}{12} & 7 & 3 & 2 & 0 \\
\hline & & $38.4 \%$ & $30.7 \%$ & $30.7 \%$ & $0 \%$ & & $58.4 \%$ & $25 \%$ & $16.6 \%$ & $0 \%$ \\
\hline \multirow{2}{*}{ Commu-Nity } & \multirow{2}{*}{12} & 6 & 6 & 0 & 0 & \multirow{2}{*}{13} & 9 & 4 & 0 & 0 \\
\hline & & $50 \%$ & $50 \%$ & $0 \%$ & $0 \%$ & & $69.2 \%$ & $30.8 \%$ & $0 \%$ & $0 \%$ \\
\hline
\end{tabular}

According to the above table $69.3 \%$ of the cases with household as their ambulatory status in group A had excellent to good outcome which was less compared to $83.4 \%$ of the cases in group B but the difference was not significant. While in Community as their ambulatory status both groups have $100 \%$ excellent to good outcome.

\section{Case Illustration}

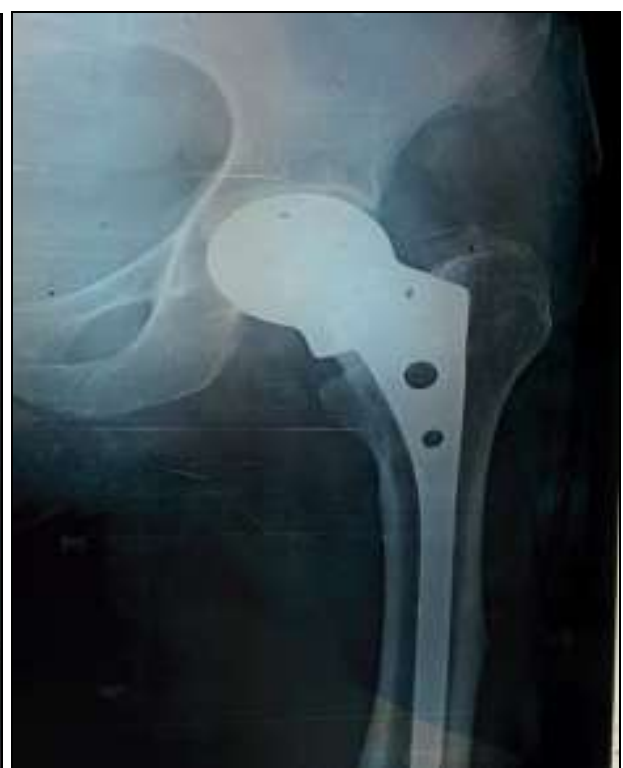

B. At 1 Year

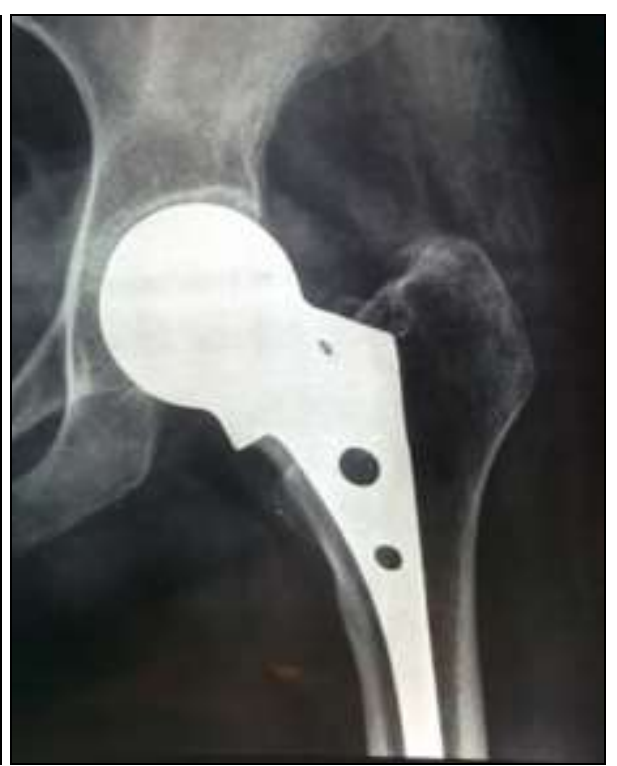

D. At 3rd Year

C. At $2^{\text {nd }}$ Year.

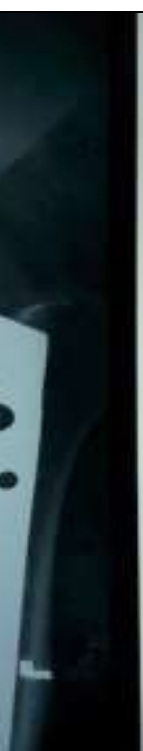

Fig 2(A-D): Uni-polar Hemiarthroplasty Case 1 


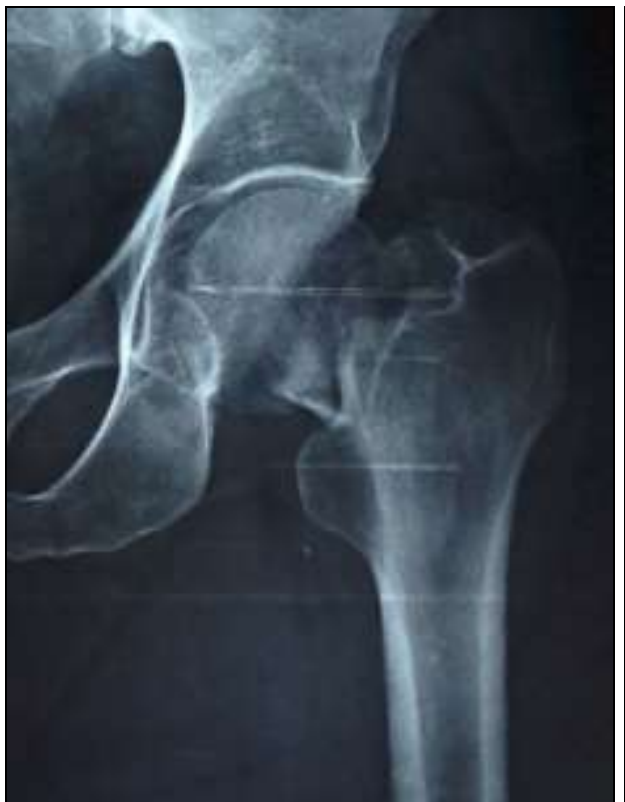

A. Pre-operative.

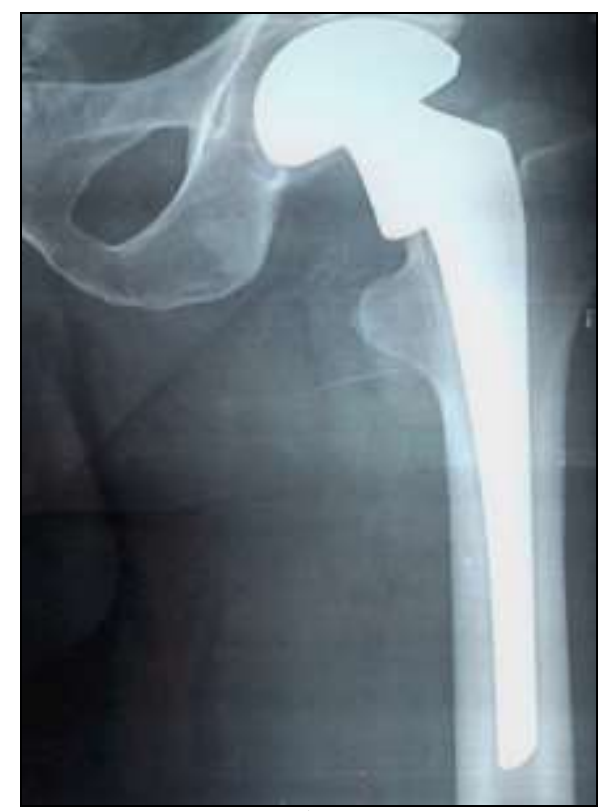

C. At $2^{\text {nd }}$ year.

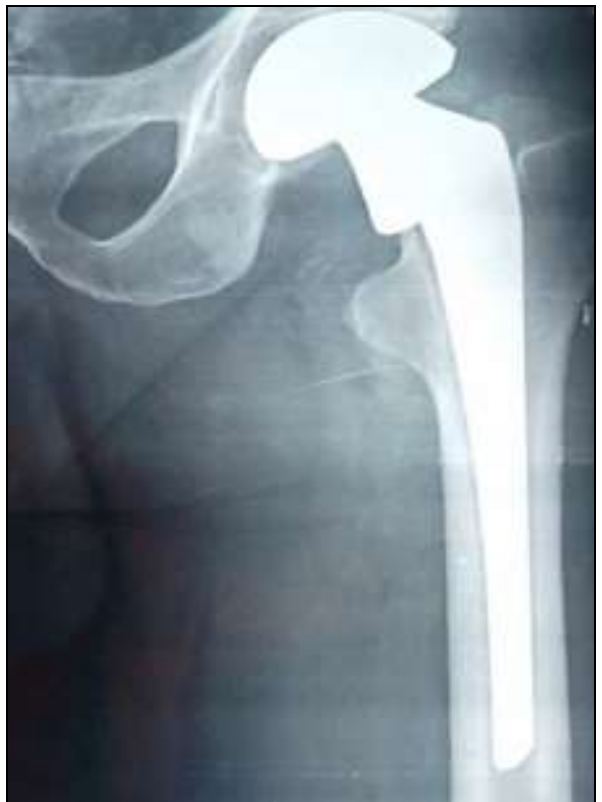

B. At 1 Year

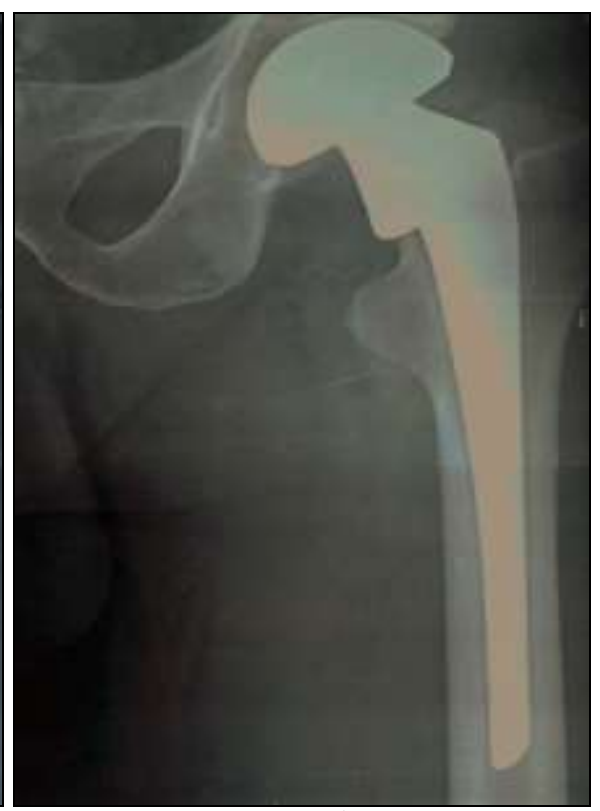

D. At $3^{\text {rd }}$ Year

Fig 3(A-D): Bi-polar Hemiarthroplasty Case 2

\section{Discussion}

In our study, we used the Harris Hip Score $^{8}$ as a basis of functional outcome assessment. It incorporates all-important variables into single reliable figure, which is both reproducible and reasonably objective. In our study, mean age in Group A and Group B was 76 and 72 years respectively. Nottage et al. [6] reported mean ages in Austin Moore prosthesis and Bipolar is 73 and 65 years respectively which is comparable to our study.

Nottage et al. ${ }^{[6]}$ reported a mean HHS of 85 in case of bipolar hemiarthroplasty and 77 in cases operated with Austin Moore's prosthesis though the $p$ value was not significant. In another study by Marya et al. ${ }^{[9]}$ reported average HHS of 81 in 80 subjects operated with Bipolar prosthesis. The results in the current study were comparable to those mentioned above that is mean HHS of 92 in subjects operated with bipolar and 84 in subjects operated with Austin Moore's Prosthesis.

In the present study, the rate of superficial infection was $7.1 \%$ in group A and 7.4\% in Group B which is comparable with other similar studies ${ }^{[10]}$. The rate of superficial infection is not statistically significant between two groups. The rate of infection has been kept low by use of various measures like use of prophylactic antibiotics. The infection rate has been reported high when posterior approach is used for arthroplasty due to proximity of the incision to the perineum ${ }^{11}$. Subject who developed infections had to stay longer in the hospital. Management of superficial infections was done with appropriate frequent dressings and antibiotics according to culture and sensitivity reports. In our study we did not encountered any deep infection.

Sciatic nerve injuries can occur due to various causes like direct trauma, traction, pressure of retractors, positioning of extremity, and limb lengthening. Incidence of such injuries is $0.7 \%$ to $3.5 \%{ }^{[12]}$ which is less comparable to the rate in the current study (7.4\%). Sciatic nerve palsy in our study is due to retaining of excessive neck length and traction.

Some randomized trials show identical rate of dislocation for both unipolar and bipolar prostheses ${ }^{[13,14]}$ which is similar to our study. In our study rate of dislocation with bipolar prosthesis is $3.7 \%$ and with Austin Moore prosthesis is $7.1 \%$ 
but the difference is not statistically significant. Drinker and Murray $^{15}$ found that dislocation of unipolar prosthesis was reduced successfully with closed methods and dislocations of bipolar reduced by open methods. Inter-prosthetic dislocation of a bipolar prosthesis in which the head separates from the stem invariably leads to open reduction. Failure of closed reduction is related to disassembly of bipolar prosthesis. In our study we did open reduction for 1 subject in group B even in the absence of inter-prosthetic dislocation as movement of the head prevented closed reduction.

In the current study we had two cases of acetabular erosion on serial anteroposterior X-rays at periodic follow up both were Grade I where there is reduction of joint space present, both from Group A, although both had pain in the hip and had good range of motion. Both of these subjects in our study were more than 75 years of age who had poor function initially but achieved fair function at final follow-up. No acetabular erosion seen in group B. Superiority of bipolar over unipolar prosthesis has been reported with respect to decreased or absent acetabular erosion [16]. Some studies suggest the findings with reference to acetabular erosion in unipolar and bipolar prostheses appeared to be quite similar $[17,18]$.

In our study, 1 subject from both groups expired due to myocardial infarction with in 6 months of follow up. 1 subject from group A developed stroke and expired at 18 months after surgery, 1 subject from both groups expired after 24 months follow up due to unknown cause. Lower rate of mortality comparable to other series is probably due to proper selection of cases, proper management of the associated medical problems preoperatively, routine use of antibiotics and most important was early mobilization.

\section{Conclusion}

In our study comparison between unipolar and bipolar arthroplasty, bipolar group has slightly better functional outcome which is statistically insignificant. Complications are comparable in both group, bipolar group has disadvantage in postoperative dislocations where close reduction fails often needs open reductions. Advantage of unipolar is its cheap, short operative time, easy implantation, less blood loss. Based on the results of our study, unipolar and bipolar has its own advantages and disadvantages, we recommend unipolar arthroplasty in less ambulatory, low socioeconomic status, subjects with medical illnesses with short life expectancy. Bipolar arthroplasty in elderly medically fit individuals who are physically active community ambulators.

\section{Declaration \\ Funding: None \\ Conflict of interest: None declared \\ Ethical approval: Not required}

\section{References}

1. Bray TJ, et al. The displaced femoral neck fracture: internal fixation versus bipolar endoprosthesis. Clin Orthop 1988;230:127-40.

2. Lu-Yao GL, et al. Outcomes after displaced fractures of the femoral neck: a metaanalysis of 106 published reports. JBJS Am 1994;76-A:15-25.

3. Rogmark C. A prospective randomized trial of internal fixation versus arthroplasty for displaced fractures of the neck of femur. JBJS Br 2002;84-B:183-8.

4. Hudson, et al. 8 yr. outcome associated with clinical options in management of femoral neck fractures. Clin
Orthop 1998;348:59-66.

5. Narayan KK, George T. Functional outcome of fracture neck of femur treated with total hip replacement versus bipolar arthroplasty in a South Asian population. Arch Orthop Trauma Surg 2006;126(8):545-8.

6. Nottage McMaster, et al. Comparison of bipolar implants with fixed neck prostheses in femoral neck fractures. Corr 1990;251:38-43.

7. Wathne RA, Koval KJ, Aharonoff GB, et al. Modular unipolar versus bipolar prosthesis: a prospective evaluation of functional outcome after femoral neck fracture. J Orthop Trauma 1995;9:298-302.

8. Harris H. Harris hip score. JBJS (Am) 1969;51A(4):73755.

9. Marya SKS, Thukral R, et al. Prosthetic replacement in femoral neck fracture in the elderly: results and review of the literature. IJO 2008;42(1):61-67.

10. Ong $\mathrm{BC}$ et al. Unipolar Vs Bipolar hemiarthroplasty: functional outcome after femoral neck fracture at a minimum of 36 months of follow up. J Orthop trauma 2002;16(5):317-322.

11. Ahmad I. Mortality and morbidity in elderly subjects with fracture neck of femur treated by hemiarthroplasty, J Coll Physicians Surg Pak 2006;16(10):655-8.

12. James Harkess: Campbell's operative orthopaedics., 10th edition 2003;1:315.

13. Parker, et al. Arthroplasties for proximal femoral fractures in adults. The Cochrane library 2001, 3 .

14. Long, Knight. Bateman UPF prosthesis in fractures of femoral neck. CORR 1980;152:198-201.

15. Drinker, Murray. The universal proximal femoral endoprosthesis- a short term comparison with conventional hemiarthroplasty. JBJS 1979;61-A:11671174.

16. Devas, Hinves. Prevention of acetabular erosion after hemiarthroplasty for fracture neck of femur. JBJS $\mathrm{Br}$ 65:548-551.

17. Kaltsas Klugman, et al. Acetabular erosion - a comparison between Austin Moore and monk hard top prosthesis. Injury 1986;17:230-236.

18. Dalldorf. Rate of degeneration of acetabular cartilage after hemiarthroplasty - JBJS (A) 1995;77:877-88. 